\title{
MEASURING WIND SPEED WITH ELECTROMAGNETIC INDUCTION
}

\author{
Rahul Jayawardana \\ HND (Engineering), CeEng (MIT), IET, IEEE \\ Colombo, Sri Lanka
}

\begin{abstract}
Measuring wind speed is critical and crucial for many occasions and practical applications. Weather stations, aircrafts, weather crafts and many other equipment need to read the speed of the wind constantly to successfully maintain and regulate the functionality and to deliver the maximum expected result to the end user. Other than those practical applications, wind speed is more important to conduct physical tests and the experiments in the fields of engineering and physics. In the modern world more compact and integrated anemometers can be seen that are more agile and integrated which are more effective and efficient towards giving a reliable wind speed measurement. But in smaller scales and scenarios, it is important to have a method for assembling an anemometer that can give wind speed readings with a significant level of reliability and accuracy. Within the research done on this paper a method is shown for how to calculate the wind speed based on an induced voltage signal.
\end{abstract}

\section{Keywords - Physics, Electromagnetism, Wind speed,}

\section{INTRODUCTION}

Measuring the wind speed is a one of the most important and crucial factor for many practical applications and occasions. While conducting experiments, physical tests and even to collect input data for some processes, wind speed is essential and must be measured in a reliable manner. Anemometers are the most widely used equipment to measure the wind speed $^{1}$ ). In the modern day, more integrated and compact size anemometers are present in the market for both small and industrial level operations. Anemometer is an essential equipment even for military operations. Some sniper weapon systems are including wind speed measuring devices for precision accuracy. The Kestrel 4000 weather station used for the CheyTac m200 intervention sniper rifle is a good example for this $\left({ }^{2}\right)$. And in weather stations and weather departments wind speed measuring devices are widely used to measure the wind speed as it I a one of the most crucial factor in weather forecasting. But those industrial and high standard anemometers are expensive and hard maintained and used since they are created with more sensitive parts, components and, system architectures making them easily vulnerable to the external damages or require high maintenance efforts. In this paper a new method is discussed, that is using the electromagnetic induction $\left(^{3}\right)$ principle to measure the wind speed. With this method, it is shown that an accurate and a reliable wind speed measuring anemometer can be designed and created with utilizing the electromagnetic induction principle used in the common DC motors.

\section{MATERIALS AND METHODS}

\section{Implementation of the Anemometer}

In most of the physical tests and experiments done on the fields of engineering and physics, measuring wind speed is standing as an important input. Therefore to measure the wind speed, a wind speed measuring equipment or an anemometer must be built to get the data and estimations about the wind speeds $\left({ }^{4}\right)$. The most of the anemometers used, are designed to measure relatively high wind speeds and for commercial purposes $\left({ }^{5}\right)$. The wind that is generating from small scale wind sources are in low speed compared to the other commercial purpose wind speeds. Therefore suitable and a reliable wind speed measuring device can be built with using the following components for low speed wind measurements.

- DC circuit motor

- Three wind cups (from a light and suitable material)

- Connecter wires

- Wi-Fi Microcontroller

The function or the mechanism of the following anemometer is based on the principle of the electromagnetic induction $\left({ }^{6}\right)$. That is when a general purpose circuit dc motor is rotated with an external force, it will generate and produce a voltage between its two terminals due to the electromagnetic induction. According to the datasheet of the common DC circuit motor under a voltage of $5 \mathrm{~V}-9 \mathrm{~V}$ the motor is having 9000rpm without having any load on it. And the recommended voltage for the motor to be operated is $6 \mathrm{~V}\left({ }^{7}\right)$.

The three wind cups will be fixed in 120 degrees apart from each other to make it an effective wind sensitive device like the most of the commercial purpose general anemometers. Then the wind turbine will be directly connected to the DC motor,

The two terminals from the motor is then connected to the Wi$\mathrm{Fi}$ microcontroller, for this test an ESP8266 Node MCU 


\section{International Journal of Engineering Applied Sciences and Technology, 2020 \\ Vol. 5, Issue 7, ISSN No. 2455-2143, Pages 24-26 \\ Published Online November 2020 in IJEAST (http://www.ijeast.com)}

module was used. And one terminal from the motor is directly connected to an analog input pin of the microcontroller while the other goes to the ground.

After making the basic hardware arrangement, an equation must be developed to calculate the wind speed based on the magnitude of the induced voltage. The program or the code including the equation for the calculation written using the Arduino IDE can then be uploaded in to the Node MCU.

The voltage signals coming from the motor can then be processed according to the equation developed and the, results can be shown in the serial monitor of the Arduino IDE or using the Blynk app it can be displayed on the smart phone.

The following block diagram shows the system architecture of the anemometer which is considered in this research.

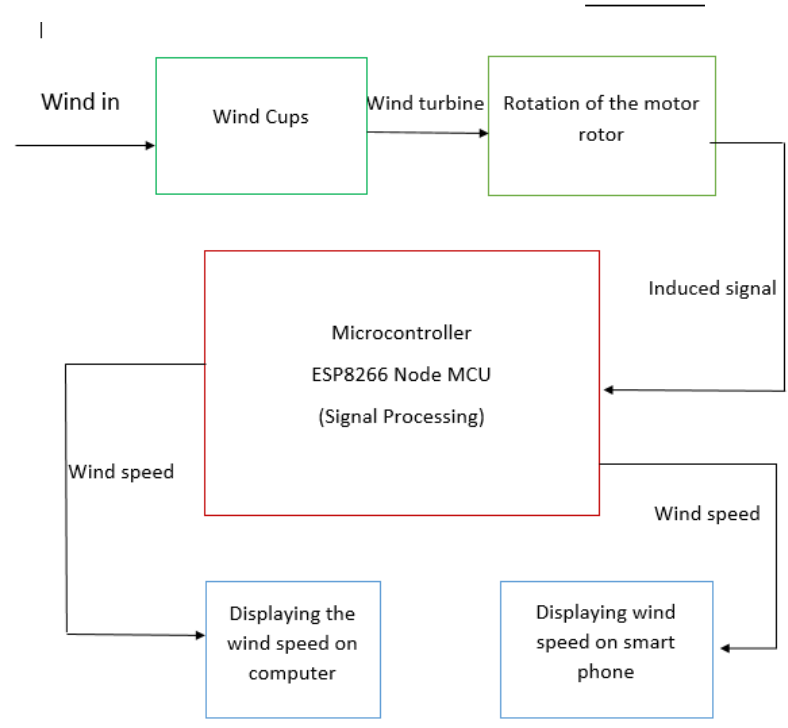

Diagram 01 - The block diagram of the anemometer and its functions

\section{EXPERIMENT AND RESULT}

\section{Obtaining the Wind speed from the Anemometer}

For the implementation of the anemometer a DC circuit motor will be used and according to the data from the datasheet, the motor is having the following characteristics and behaviors. And using them to get an equation showing the connection between the induced voltage and the wind speed.

RPM given in the datasheet $=9100+/ \_1800 \mathrm{rpm}$

Since a fixed RPM is required for the calculations, a half of the fluctuating value will be taken in to consideration

$$
\text { Fluctuation value }=1800 / 2=900 \mathrm{rpm}
$$

Then, the RPM value $=9100+900=10000 \mathrm{rpm}$

The voltage and the RPM of a DC motor is showing a linear connection,
In this calculation the recommended voltage of $6 \mathrm{~V}$ will be taken in to consideration

Calculating the rounds per one volt,

$$
\begin{gathered}
6 \mathrm{~V}=10000 \mathrm{rpm} \\
1 \mathrm{~V}=1666.66 \mathrm{rpm}
\end{gathered}
$$

The speed of the air $=\mathrm{V}_{\text {Air }}$

If the friction of the motor rotor is negligible, then the wind turbine of the anemometer should rotate in the same speed as the outside wind speed.

Rotating speed of the wind turbine $=\mathrm{V}_{\text {Turbine }}=\mathrm{V}_{\text {Air }}$ Angular velocity of the turbine,

$r=$ the radius of the wind turbine

$$
\begin{aligned}
& \mathrm{V}=\mathrm{r} \omega \\
& \omega=\mathrm{V}_{\text {Air } / \mathrm{r}}
\end{aligned}
$$

The frequency of the turbine rotation,

$$
\begin{aligned}
& 2 \pi \mathrm{f}=\omega \\
& \mathrm{f}=\omega / 2 \pi=\left(\mathrm{V}_{\text {Air }} \times 2 \pi\right) / \mathrm{r}
\end{aligned}
$$

The frequency of the RPM divided by 60 because the, RPM represents the revolutions per minute, while the frequency represents revolutions per second. Therefore RPM can be obtained through multiplying the frequency from 60 ,

$$
\begin{aligned}
& \mathrm{RPM}=\mathrm{f} \times 60 \\
& \mathrm{RPM}=\frac{120 \pi \times \mathrm{V}_{\text {Air }}}{\mathrm{r}}
\end{aligned}
$$

The voltage generated, $1666.66 \mathrm{rpm}=1 \mathrm{~V}$, then,

$$
\begin{aligned}
\text { Induced voltage } & =(1 / 1666.66) \times\left(120 \pi \mathrm{V}_{\text {Air }} / \mathrm{r}\right) \\
& =120 \pi \mathrm{V}_{\text {Air }} / 1666.66 \mathrm{r}
\end{aligned}
$$

Calculating the $\mathrm{V}_{\text {Air }}$ from induced voltage,

$$
\mathrm{V}_{\text {Air }}=\frac{1666.66 r \mathrm{~V}_{\text {Induced }}}{120 \pi}
$$

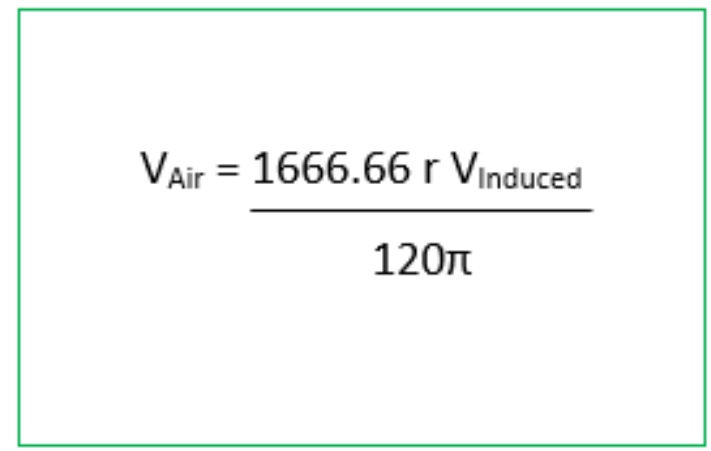

For this research the radius of the wind turbine is equal to $10.5 \mathrm{~cm}$ which is $0.105 \mathrm{~m}$.

Radius $=10.5 \mathrm{~cm}=0.105 \mathrm{~m}$

Then according to the above mentioned equation, the speed of the wind can be calculated as follows.

$$
\begin{aligned}
\mathrm{V}_{\text {Air }} & =\frac{1666 / 66 \times 0.105 \times \mathrm{V}_{\text {Induced }}}{120 \times 3.14} \\
\mathrm{~V}_{\text {Air }} & =\frac{174.9993 \times \mathrm{V}_{\text {Induced }}}{376.8}
\end{aligned}
$$


$\mathrm{V}_{\text {Air }}=0.4644 \mathrm{~V}_{\text {Induced }}$

\section{CONCLUSION}

Unlike the most common anemometers that are expensive and hard to be obtained, with the use of the electromagnetic induction principle, the wind speed can be measured with a more easy way that can be used for conducting small scale researches and to collect wind speed data. And it is important to note that, with the use of this method more complex and more accurate wind speed readings can be obtained with changing the sensitivity of the motor using. Since the friction of the rotor in the motor using can reduce the strength of the induced signal, application of bearings and lubricants can increase the sensitivity and the accuracy of the wind speed readings.

\section{REFERENCE}

[1]. "Devices That Measure Wind Speed." n.d. Accessed October 29, 2020. https://sciencing.com/devicesmeasure-wind-speed-4818.html.

[2]. "Electromagnetic Induction and Faradays Law." n.d. Accessed October 30, 2020. https://www.electronicstutorials.ws/electromagnetism/electromagneticinduction.html.

[3]. "HOW TO MEASURE WIND SPEED." n.d. $\begin{array}{lll}\text { Accessed } & \text { October } & 2020 .\end{array}$ https://www.windcrane.com/blog/windcranegeneral/how-measure-wind-speed.

[4]. "Kestrel 4000NV Weather \& Environmental Meter with Bluetooth in Olive Drab." n.d. Accessed November 16, 2020. https://kestrelinstruments.com/kestrel-4000nvweather-environmental-meter-with-bluetoothrclassic-in-olive-drab-1.

[5]. "Toy/Hobby DC Motor Pinout Wiring, Specifications, Uses Guide and Datasheet." n.d. Accessed October 30, 2020. https://components101.com/motors/toy-dc-motor.

[6]. "Wind Measurement - an Overview | ScienceDirect Topics." n.d. Accessed October 29, 2020. https://www.sciencedirect.com/topics/earth-andplanetary-sciences/wind-measurement. 